\title{
RESEARCH
}

\section{PREVALENCE AND CLINICAL FEATURES OF CHRONIC CRITICAL ILLNESS IN THE ELDERLY POPULATION IN TURKEY}

Turkish Journal of Geriatrics DOI: 10.31086/tjgeri.2020.188 2020; 23(4): 501-508

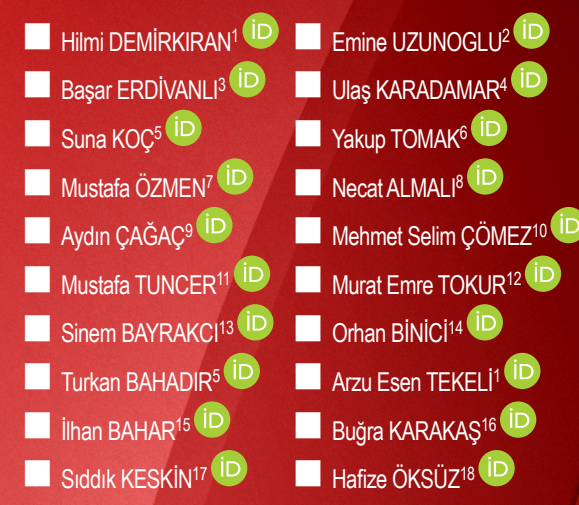

CORRESPONDANCE

${ }^{1}$ Hilmi DEMIRKIRAN

Van Yuzuncu Yil University Faculty of

Medicine, Department of Anesthesiology and

Reanimation, Van, Turkey

\section{Phone: +905336676188}

e-mail: h.demirkiran@yyu.edu.tr

Received: Aug 29, 2020

Accepted: Nov 24, 2020

1 Van Yuzuncu Yil University Faculty of Medicine, Department of Anesthesiology and Reanimation, Van, Turkey stanbul Medipol University Mega Hospitals Complex, Department of Anesthesiology and Reanimation, Istanbul, Turkey Recep Tayyip Erdogan University Faculty of Medicine, Department of Anesthesiology and Reanimation, Rize, Turkey 4 Private Turkey and Reanimation, Istanbul, Turkey Sakarya University Faculty of Medicine, Anesthesiology and Intensive Care Unit, Sakarya, Turkey
Private Corlu Vatan Hospital, General Intensive Care Unit, Tekirdag

Turkey
Van Yuzuncu Yil University Faculty of Medicine, Department of General Surgery, Van, Turkey Neurology, Van, Turkey versity Tayfur Ata Sokmen Faculty of Medicine, Department of Anesthesiology and Reanimation, Hatay, Turkey Van Yuzuncu Yil University Faculty of Medicine, Department of Cardiology, Van, Turkey Kutahya Health Sciences University Evliya Celebi Training and Research Hospital, Internal Medicine Crítical Care Unit, Kutahya,

Turkey
Gaziantep Provincial Directorate of Health Gaziantep Sehitkamil State Hospital, General Intensive Care Unit, Gaziantep, Turkey Harran University Faculty of Medicine, Department of Anesthesiology and Reanimation, Sanliurfa, Turkey Izmir Katip Celebi University Ataturk Training and Research Hospital Internal Medicine Critical Care Unit, Izmir, Turkey Van Health Sciences University Van Training and Research Hospita Anesthesiology Intensive Care Unit, Van, Turkey Van Yuzuncu Yil University Faculty of Medicine, Department of Biostatistics, Van, Turkey

\section{Abstract}

Objectives: The definition of chronic critical illness in the elderly has not yet been determined. The aim of the study is to determine the prevalence and clinical features of chronic critical illness in the elderly population in Turkey.

Materials and Methods: Data from 16 intensive care units of public and private hospitals in Turkey were evaluated. Patients staying in the intensive care units for at least eight days between 2015 and 2017 and having at least one of the additional criteria were accepted as chronic critical illness and they were divided into two groups by age, those 65 and older and those under 65 .

Results: The chronic critical illness patient rate in the intensive care units was $10.7 \%$. Of chronic critical illness patients in the intensive care units, $60.9 \%$ were 65 years of age and older, and the mortality rate of patients 65 years and older was $70 \%$. The frequencies of ischemic stroke and sepsis, the number of patients with comorbidities, and the mortality rate were higher in patients over 65 years of age, while the frequency of traumatic brain injury, presence of a major wound, tracheostomy, length of hospital stay and cost of care were higher in patients under 65 years of age.

Conclusion: We determined that prolonged mechanical ventilation, traumatic brain injury, tracheostomy and major wound presence in intensive care units patients 65 years and older increased hospital stay and costs. More work is needed to define chronic critical illness more clearly in elderly.

Keywords: Chronic Disease; Critical Illness; Intensive Care Unit; Aged; Turkey 


\section{INTRODUCTION}

As a result of improvements in treatment in the intensive care unit (ICU), more patients survive acute critical illness. However, some of these patients have to live with long-term dependence on mechanical ventilation and other intensive care treatments (1). These patients who survive in the ICU and subsequently face a complex healing trajectory are described as chronic critical illness (CCl). It is increasingly recognized that patients with $\mathrm{CCl}$ are prone to psychological, physical, and cognitive dysfunction both during their stay in the hospital and after discharge (2). As a result of a recent consensus, patients who remained in the ICU for at least eight days and exhibited at least one of the following five conditions were defined as $\mathrm{CCl}$ : prolonged mechanical ventilation $(\mathrm{PMV})>96$ hours extended; tracheostomy; serious injuries and / or multiple organ failure; sepsis or others serious infections; ischemic stroke, intracerebral bleeding, or traumatic brain injury (TBI)(3).

The presence of various risk factors such as chronic kidney failure, frailty, repeated admissions to the ICU, and older age are indicators of poor prognosis in $\mathrm{CCl}$ patients (3). There has been an increase in the elderly population admitted to the ICU annually for the last two decades (4). The definition of $\mathrm{CCl}$ in the elderly has not yet been determined, thus preventing accurate analysis of elderly people with $\mathrm{CCl}$.

Although there has been a comprehensive discussion of $\mathrm{CCl}$ in the elderly population worldwide, $\mathrm{CCl}$ in the elderly has not been studied much in Turkey. The aim of this multicenter study is to determine the prevalence, clinical features, and characteristics of $\mathrm{CCl}$ in the elderly population in Turkey.

\section{MATERIALS AND METHODS}

A retrospective crossectional study was conducted in five different regions of Turkey between July
2017 and June 2018. The study was approved by the Non-Interventional Van Yuzuncu Yil University Clinical Ethics Committee (June 20, 2017; No. 08). In addition, approval was obtained from the official administrations of the researchers they worked with who agreed to participate in the study. The medical records of patients treated in the ICU between 2015 and 2017 were evaluated. The study was registered at ClinicalTrials.gov (identifier: NCT03262883).

Patients staying in the ICU for at least eight days and having at least one of the additional criteria were accepted as $\mathrm{CCl}$ (PMV, tracheostomy, sepsis, major wound, stroke, or TBI). CCl patients included in the study were also divided into two groups, 65 years and older and under 65 years. Patients with illnesses other than $\mathrm{CCl}$, length of ICU stay of $\leq 7$ days, and age $<18$ years were excluded from the study.

\section{Statistical Analysis}

The data were evaluated in the IBM SPSS Statistics Standard Concurrent User V 25 (IBM Corp., Armonk, New York, USA) statistical program. For descriptive statistics, unit number (n), percent $(\%)$, mean \pm standard deviation $(\bar{x} \pm \mathrm{ss})$, median $(\mathrm{M})$, smallest value (min), largest value (max), first quartile (Q1) and third quartile (Q3) and interquartile distance (IQR -Interquartile range) are given as values. Pearson Chi-square test was used to compare categorical variables between groups. In case of a difference in Pearson Chi-square test, two proportion $z$ tests with Bonferroni correction were used. The normal distribution of data of numerical variables was evaluated by Shapiro-Wilk normality test and Q-Q graphs. Since the data did not show normal distribution, two groups were compared with Mann-Whitney $U$ test and three groups were compared with Kruskal-Wallis analysis. A $p<.05$ value was considered statistically significant. 


\section{RESULTS}

Among 23,272 patients admitted to ICUs during the study period, 2,493 (10.7\%) were CCl. Demographic characteristics and the clinical features of the $\mathrm{CCl}$ patients are presented in Table 1.

PMV rate is high in both groups and shows similar distribution between groups $(p=.300)$. The frequencies of ischemic stroke $(p<.001)$ and sepsis $(p<.001)$ in patients 65 years and older were significantly higher than in patients under 65 years (Table 2).

The number of patients with one, two, or three comorbid diseases in the 65 and older age group was significantly higher than in the under 65 age group. The mortality rate was higher in the 65 and older group (Table 3).

Comparison of PMV, TBI, major wound, sepsis and tracheostomy with mortality, duration of hospitalization and cost are given in table 4 . The duration of hospitalization with PMV, sepsis and tracheostomy were significantly higher in both groups. The duration of hospital stay for those with $\mathrm{TBI}$ and major wound in the 65 and older age group was significantly longer. The mortality rate of patients with sepsis, tracheostomy and without $\mathrm{TBI}$ in the overall patient group were significantly higher.

\section{DISCUSSION}

There are no clear criteria for defining the transition of patients with $\mathrm{CCl}$ from the acute phase to the chronic phase (3). In this study, we have determined the $\mathrm{CCl}$ criteria as a stay in the ICU of eight or more days and at least one of the six clinical causes (major wound, sepsis, stroke, PMV, tracheostomy, or TBI) in accordance with the literature. Among 23,272 patients admitted to ICUs during the study period, $2,493(10.7 \%)$ were $\mathrm{CCl}$. The rate of $\mathrm{CCl}$ seen in our study is similar to the rates reported by other authors $(5 \%$ to $15 \%)(5,6)$. CCl-associated hospital mortality rates were $61 \%$ in the this study, $65 \%$ in a multicenter study in Brazil in 2015, and 50\% in a study conducted in Mexico (7). The in-hospital mortality rate was $10 \%$ in a study conducted in New Zealand and Australia (8). In the US, which is a developed country, $\mathrm{CCl}$-associated in-hospital mortality rate was $31 \%$ (9). Our mortality results are higher than those of developed countries and similar to those of developing countries.

Elderly patients account for 10 to $20 \%$ of all ICU admissions, and this number is growing steadily (10). In another study, the percent of patients over 65 years of age in the ICU was 53\%, according to data from training hospitals (11). In our study, the rate of elderly $\mathrm{CCl}$ patients staying in the ICU was $60.9 \%$, slightly higher than in other studies. PMV distribution was high in both groups and showed similar distribution between groups. The frequency of ischemic stroke and sepsis in patients 65 years and older was significantly higher than in patients under 65 years. The frequency of TBI, major wound presence, and tracheostomy was significantly higher in patients under 65 years of age. According to an observational study on the mortality rates of critically ill elderly patients admitted to the ICU, inhospital mortality rates are between $24 \%$ and $40 \%$, three-month mortality rates are between $39 \%$ and $41 \%$, six-month mortality rates are between $37 \%$ and $51 \%$, and one year mortality rates are between $44 \%$ and $68 \%$ (10). The one-year mortality rate was $73 \%$ in patients who had undergone mechanical ventilation for more than 14 days or underwent tracheostomy (12). In our study, the mortality rate of patients 65 years and older was 70\%, and this rate was significantly higher than in those patients under 65 years old (47.6\%).

PMV accounts for a large part of ICU costs (13). It is known that that elderly people are more sensitive to lung damage caused by PMV and the incidence of acute respiratory failure (ARF) increases significantly with age. Many studies have shown that age of patients requiring mechanical ventilation and ARF are independently associated with mortality $(14,15)$. In our study, the number of patients with chronic 
Table 1. Chronic critical illness (CCl) Characteristics

\begin{tabular}{|c|c|c|}
\hline Variables & $n$ & $\%$ \\
\hline Gender & & \\
\hline Male & 1462 & 58.6 \\
\hline Female & 1031 & 41.4 \\
\hline Age & \multirow{4}{*}{\multicolumn{2}{|c|}{$\begin{array}{c}65.5 \pm 18.7 \\
70(56-80) \\
18-101\end{array}$}} \\
\hline$x \pm s s$ & & \\
\hline$M\left(Q_{1}-Q_{3}\right)$ & & \\
\hline $\min -\max$ & & \\
\hline Hospitalization year & & \\
\hline 2015 & 557 & 22.3 \\
\hline 2016 & 1071 & 43.0 \\
\hline 2017 & 865 & 34.7 \\
\hline \multicolumn{3}{|l|}{ Number of Comorbid Diseases } \\
\hline 0 & 1354 & 54.3 \\
\hline 1 & 777 & 31.2 \\
\hline 2 & 299 & 12.0 \\
\hline 3 & 56 & 2.2 \\
\hline 4 & 7 & 0.3 \\
\hline \multicolumn{3}{|l|}{ Those with Comorbid Disease * } \\
\hline COPD & 426 & 17.1 \\
\hline DM & 457 & 18.3 \\
\hline $\mathrm{CHF}$ & 376 & 15.1 \\
\hline CLD & 36 & 1.4 \\
\hline CRF & 175 & 7.0 \\
\hline \multicolumn{3}{|l|}{ Cancer } \\
\hline Solid Cancer & 66 & 2.6 \\
\hline Hematological Cancer & 6 & 0.2 \\
\hline \multicolumn{3}{|l|}{ Primary Hospital Diagnosis } \\
\hline Respiratory Failure & 472 & 18.9 \\
\hline Medical & 696 & 27.9 \\
\hline Cardiac & 395 & 15.8 \\
\hline Neurological disease & 572 & 22.9 \\
\hline Surgery (post op) & 141 & 5.7 \\
\hline Trauma & 217 & 8.7 \\
\hline \multicolumn{3}{|l|}{ Chronic Disease Risk Factors * } \\
\hline Prolonged Mechanical Ventilation & 2369 & 95.0 \\
\hline \multicolumn{3}{|l|}{ Stroke } \\
\hline Hemorrhagic Stroke & 210 & 8.4 \\
\hline Ischemic Stroke & 377 & 15.1 \\
\hline Traumatic Brain Injury & 225 & 9.0 \\
\hline Major Wound & 87 & 3.5 \\
\hline Sepsis & 633 & 25.4 \\
\hline Tracheostomy & 764 & 30.6 \\
\hline Undefined & 39 & 1.6 \\
\hline Mediastinal & 2 & 0.1 \\
\hline Permanent & 195 & 7.8 \\
\hline Temporary & 463 & 18.6 \\
\hline
\end{tabular}




\begin{tabular}{|c|c|c|c|}
\hline $\begin{array}{l}\text { Discharge Status } \\
\text { No } \\
\text { Yes }\end{array}$ & $\begin{array}{c}2146 \\
347 \\
\end{array}$ & & $\begin{array}{l}86.1 \\
13.9 \\
\end{array}$ \\
\hline $\begin{array}{l}\text { Referral to a More Comprehensive Hospital } \\
\text { No } \\
\text { Yes }\end{array}$ & $\begin{array}{c}2445 \\
48\end{array}$ & & $\begin{array}{c}98.1 \\
1.9\end{array}$ \\
\hline $\begin{array}{l}\text { Referral to the Same Comprehensive Hospital } \\
\text { No } \\
\text { Yes }\end{array}$ & $\begin{array}{c}2491 \\
2\end{array}$ & & $\begin{array}{c}99.9 \\
0.1\end{array}$ \\
\hline $\begin{array}{l}\text { Transfer to Palliative Unit } \\
\text { No } \\
\text { Yes }\end{array}$ & $\begin{array}{c}2455 \\
38\end{array}$ & & $\begin{array}{c}98.5 \\
1.5\end{array}$ \\
\hline $\begin{array}{l}\text { Transfer to Service } \\
\text { No } \\
\text { Yes }\end{array}$ & $\begin{array}{c}2466 \\
27\end{array}$ & & $\begin{array}{c}98.9 \\
1.1\end{array}$ \\
\hline $\begin{array}{l}\text { Hospitalization Status In Intensive Care } \\
\text { No } \\
\text { Yes }\end{array}$ & $\begin{array}{c}2438 \\
55\end{array}$ & & $\begin{array}{c}97.8 \\
2.2\end{array}$ \\
\hline $\begin{array}{l}\text { Refuse Treatment } \\
\text { No } \\
\text { Yes }\end{array}$ & $\begin{array}{c}2416 \\
77 \\
\end{array}$ & & $\begin{array}{c}96.9 \\
3.1 \\
\end{array}$ \\
\hline $\begin{array}{l}\text { Survival } \\
\text { Living } \\
\text { Died }\end{array}$ & $\begin{array}{l}967 \\
1526\end{array}$ & & $\begin{array}{l}38.8 \\
61.2\end{array}$ \\
\hline $\begin{array}{l}\text { Time on Mechanical Ventilator (Days) } \\
x \pm s s \\
M\left(Q_{1}-Q_{3}\right) \\
\text { min-max }\end{array}$ & \multicolumn{3}{|c|}{$\begin{array}{c}27.2 \pm 30.8 \\
17(10-33) \\
0-355\end{array}$} \\
\hline $\begin{array}{l}\text { Time spent in intensive care (Days) } \\
x \pm s s \\
M\left(Q_{1}-Q_{3}\right) \\
\text { min-max }\end{array}$ & \multicolumn{3}{|c|}{$\begin{array}{c}31.4 \pm 32.4 \\
21(13-37) \\
8-384\end{array}$} \\
\hline $\begin{array}{l}\text { Length of hospital stay (Days) } \\
\times \pm s s \\
M\left(Q_{1}-Q_{3}\right) \\
\min -\max \end{array}$ & \multicolumn{3}{|c|}{$\begin{array}{c}34.9 \pm 36.4 \\
23(14-41) \\
8-384\end{array}$} \\
\hline $\begin{array}{l}\text { Cost after the 8th day }(\$) \\
\times \pm \text { ss } \\
M\left(Q_{1}-Q_{3}\right) \\
\text { min-max }\end{array}$ & \multicolumn{3}{|c|}{$\begin{array}{c}7774.8 \pm 12444.1 \\
4104.6(1655.9-9449.3) \\
0.61-304252.9\end{array}$} \\
\hline $\begin{array}{l}\text { Money Paid by Insurance }(\$) \\
x \pm s s \\
M\left(Q_{1}-Q_{3}\right) \\
\min -\max \end{array}$ & \multicolumn{3}{|c|}{$\begin{array}{c}10116.2 \pm 11252.8 \\
6358.6(3753.4-12242.1) \\
526.5-12242.1\end{array}$} \\
\hline
\end{tabular}

* Each disease was evaluated separately. COPD: Chronic Obstructive Pulmonary Disease, DM: Diabetes Mellitus, CHF: Chronic Heart Failure, CRF: Chronic Renal Failure, CLD: Chronic Liver Disease 
Table 2. Comparison of Chronic Critical Illness Risk Factors, Hospitalization Times and Costs by Age.

\begin{tabular}{|c|c|c|c|c|c|c|c|c|c|c|c|c|c|c|c|c|}
\hline & \multicolumn{2}{|c|}{ PMV n(\%) } & \multicolumn{3}{|c|}{ Stroke $n(\%)$} & \multicolumn{2}{|c|}{ TBI $n(\%)$} & \multicolumn{2}{|c|}{ MW n(\%) } & \multicolumn{2}{|c|}{ Sepsis n(\%) } & \multicolumn{2}{|c|}{$\begin{array}{c}\text { Tracheostomy } \\
\mathrm{n}(\%)\end{array}$} & \multirow{2}{*}{\begin{tabular}{|c|}
$\mathrm{DHS}$ \\
$\mathrm{M}\left(\mathrm{Q}_{1^{-}}\right.$ \\
$\left.\mathrm{Q}_{3}\right)$ \\
\end{tabular}} & \multirow{2}{*}{\begin{tabular}{|c|}
$\begin{array}{c}\text { DHS in } \\
\text { ICU }\end{array}$ \\
$\mathrm{M}\left(\mathrm{O}_{1}-\right.$ \\
$\left.\mathrm{Q}_{3}\right)$ \\
\end{tabular}} & \multirow{2}{*}{\begin{tabular}{|c} 
Cost \\
$\mathrm{M}\left(\mathrm{Q}_{1}-\right.$ \\
$\left.\mathrm{Q}_{3}\right)$ \\
\end{tabular}} \\
\hline & No & Yes & No & HS & IS & No & Yes & No & Yes & No & Yes & No & Yes & & & \\
\hline$<65(n=975)$ & $43(4.4)$ & $\begin{array}{c}932 \\
(95.6) \\
\end{array}$ & $\begin{array}{c}791 \\
(81.1) \\
\end{array}$ & $87(8.9)$ & $97(9.9)$ & $\begin{array}{c}841 \\
(86.3)\end{array}$ & $\begin{array}{c}134 \\
(13.7)\end{array}$ & $\begin{array}{c}924 \\
(94.8) \\
\end{array}$ & $51(5.2)$ & $\begin{array}{c}767 \\
(78.7) \\
\end{array}$ & $\begin{array}{c}208 \\
(21.3) \\
\end{array}$ & $\begin{array}{c}643 \\
(65.9) \\
\end{array}$ & $\begin{array}{c}332 \\
(34.1)\end{array}$ & 25 (29) & $22(26)$ & \begin{tabular}{|l|}
4416.4 \\
$(9101.1)$
\end{tabular} \\
\hline$\geq 65(n=1518)$ & $81(5.3)$ & $\begin{array}{l}1437 \\
(94.7)\end{array}$ & $\begin{array}{l}1115^{b} \\
(73.5)\end{array}$ & $\begin{array}{l}123^{a} \\
(8.1)\end{array}$ & $\begin{array}{l}280^{\mathrm{b}} \\
(18.4)\end{array}$ & $\begin{array}{l}1427^{b} \\
(94.0)\end{array}$ & $\begin{array}{l}91^{b} \\
(6.0)\end{array}$ & $\begin{array}{l}1482^{b} \\
(97.6)\end{array}$ & $\begin{array}{l}36^{\mathrm{b}} \\
(2.4)\end{array}$ & $\begin{array}{l}1093^{b} \\
(72.0)\end{array}$ & $\begin{array}{l}425^{b} \\
(28.0)\end{array}$ & $\begin{array}{l}1086^{b} \\
(71.5)\end{array}$ & $\begin{array}{l}432^{b} \\
(28.5)\end{array}$ & $22(26)$ & $21(23)$ & $\begin{array}{c}3981.9 \\
(9542.2)\end{array}$ \\
\hline$\chi^{2}, z$ & \multicolumn{2}{|c|}{1.076} & \multicolumn{3}{|c|}{33.392} & \multicolumn{2}{|c|}{43.416} & \multicolumn{2}{|c|}{14.411} & \multicolumn{2}{|c|}{13.917} & \multicolumn{2}{|c|}{8.737} & 2.950 & 0.951 & 1.810 \\
\hline p & \multicolumn{2}{|c|}{.300} & \multicolumn{3}{|c|}{$<.001$} & \multicolumn{2}{|c|}{$<.001$} & \multicolumn{2}{|c|}{$<.001$} & \multicolumn{2}{|c|}{$<.001$} & \multicolumn{2}{|c|}{$<.001$} & .003 & .341 & .070 \\
\hline
\end{tabular}

PMV, Prolonged Mechanical Ventilation; TBI, Traumatic Brain Injury; DHS, Duration of Hospital Stay (days); ICU, Intensive care unit; Cost, Cost after the 8th Day (\$); HS, Hemorrhagic Stroke; IS; Ischemic Stroke. z: Mann-Whitney U test, $\chi^{2}$ : Chi-square test; The superscripts a and $b$ indicate the difference of age groups between categories.

Table 3. Comparison of Number of Comorbidities, Types of Comorbidities, and Mortality by Age

\begin{tabular}{|c|c|c|c|c|c|c|c|c|c|c|c|c|c|c|c|c|c|c|c|c|}
\hline & \multicolumn{5}{|c|}{$\mathrm{CD} n(\%)$} & \multicolumn{2}{|c|}{ COPD n(\%) } & \multicolumn{2}{|c|}{ DM n(\%) } & \multicolumn{2}{|c|}{ CHF $n(\%)$} & \multicolumn{2}{|c|}{ CLD n(\%) } & \multicolumn{2}{|c|}{ CRF $n(\%)$} & \multicolumn{3}{|c|}{ Cancer $n(\%)$} & \multicolumn{2}{|c|}{ Mortality $n(\%)$} \\
\hline & 0 & 1 & 2 & 3 & 4 & No & Yes & No & Yes & No & Yes & No & Yes & No & Yes & No & SC & $\mathrm{HC}$ & No & Yes \\
\hline$<65$ & $665^{a}$ & $221^{a}$ & $78^{\mathrm{a}}$ & $10^{\mathrm{a}}$ & $1^{\mathrm{a}}$ & $870^{a}$ & $102^{\mathrm{a}}$ & $855^{a}$ & $120^{\mathrm{a}}$ & $904^{a}$ & $71^{a}$ & 959 & 16 & $931^{a}$ & $44^{\mathrm{a}}$ & $937^{\mathrm{a}}$ & $33^{\mathrm{a}}$ & $5^{a}$ & $511^{a}$ & $464^{a}$ \\
\hline$(n=975)$ & $\% 68.2$ & $\% 22.7$ & $\% 8.0$ & $\% 1.0$ & $\% 0.1$ & $\% 89.2$ & $\% 10.8$ & $\% 87.7$ & $\% 12.3$ & $\% 92.7$ & \%7.3 & \%98.4 & \%1.6 & $\% 95.5$ & $\% 91.4$ & $\% 96.1$ & $\% 3.4$ & $\% 0.5$ & $\% 52.4$ & $\% 47.6$ \\
\hline$\geq 65$ & $689^{b}$ & $556^{\mathrm{b}}$ & $221^{b}$ & $46^{b}$ & $6^{a}$ & $1197^{b}$ & $321^{b}$ & $1181^{b}$ & $337^{b}$ & $1213^{b}$ & $305^{b}$ & 1498 & 20 & $1387^{b}$ & $131^{b}$ & $1484^{b}$ & $33^{a}$ & $1^{b}$ & $456^{b}$ & 1062 \\
\hline$(n=1518)$ & $\% 45.4$ & $\% 36.6$ & $\% 14.6$ & $\% 3.0$ & $\% 0.4$ & $\% 78.9$ & $\% 21.1$ & $\% 77.8$ & $\% 22.2$ & $\% 79.9$ & $\% 20.1$ & \%98.7 & $\% 1.3$ & $\% 4.5$ & $\% 8.6$ & $\% 97.8$ & $\% 2.2$ & $\% 0.1$ & $\% 30.0$ & \% 70.0 \\
\hline$\chi^{2}$ & \multicolumn{5}{|c|}{127.755} & \multicolumn{2}{|c|}{45.123} & \multicolumn{2}{|c|}{38.808} & \multicolumn{2}{|c|}{76.068} & \multicolumn{2}{|c|}{0.437} & \multicolumn{2}{|c|}{15.417} & \multicolumn{3}{|c|}{8.383} & \multicolumn{2}{|c|}{125.135} \\
\hline P & \multicolumn{5}{|c|}{$<.001$} & \multicolumn{2}{|c|}{$<.001$} & \multicolumn{2}{|c|}{$<.001$} & \multicolumn{2}{|c|}{$<.001$} & \multicolumn{2}{|c|}{.509} & \multicolumn{2}{|c|}{$<.001$} & \multicolumn{3}{|c|}{.015} & \multicolumn{2}{|c|}{$<.001$} \\
\hline
\end{tabular}

$\chi^{2}$ : Chi-square test; a and b superscripts show the difference between age groups between categories. COPD: Chronic Obstructive Pulmonary Disease. DM: Diabetes Mellitus. CHF: Chronic Heart Failure. CRF: Chronic Renal Failure, CLD: Chronic Liver Disease

obstructive pulmonary disease (COPD), longer PMV duration, and mortality were higher in the group over 65 years old. These findings confirm the results of previous studies.

Sepsis is common in ICUs and is associated with high morbidity rates. Development of sepsis is higher in patients with $\mathrm{CCl}$ remaining in the ICU (16). In our study, the cost values after the eighth day and the mortality rates of the patients with sepsis in both groups were significantly higher than for those without $\mathrm{CCl}$. While the percentage of patients with sepsis younger than 65 years who died was $68.7 \%$, this percentage was $84.2 \%$ in the 65 and older group.

It is known that the number of comorbid diseases increases with age. Patients with comorbidities in the
ICU have higher in-hospital and long-term mortality rates (17). In our study, the number of patients with one, two, or three comorbid diseases in the 65 and older age group was significantly higher than in the group younger than 65 years old. The high mortality rate in the over 65 age group may be related to comorbid diseases as mentioned above. Studies have reported that PMV, age, presence of comorbidity, and sepsis increase mortality (18). The findings of this study reaffirm the results of previous studies.

In conclusion, this is the first study that describes the characteristics of $\mathrm{CCl}$ in the elderly population in Turkey. In this study, we observed that the mortality rate in ICU was high and mortality increased at the age of 65 and above. Moreover, we determined that 
Table 4. Comparisons for Prolonged Mechanical Ventilation, Traumatic Brain Injury, Major Wound, Sepsis and Tracheostomy.

\begin{tabular}{|c|c|c|c|c|c|c|c|c|c|c|c|c|}
\hline \multirow{3}{*}{ Variables } & \multicolumn{4}{|c|}{ All patients } & \multicolumn{4}{|c|}{$<65$} & \multicolumn{4}{|c|}{$\geq 65$} \\
\hline & \multicolumn{2}{|c|}{ No } & \multicolumn{2}{|c|}{ Yes } & \multicolumn{2}{|c|}{ No } & \multicolumn{2}{|c|}{ Yes } & \multicolumn{2}{|c|}{ No } & \multicolumn{2}{|c|}{ Yes } \\
\hline & $M$ & IQR & M & IQR & $M$ & IOR & M & IOR & M & IOR & M & IOR \\
\hline \multicolumn{13}{|l|}{$\begin{array}{c}\text { Prolonged Mechanical } \\
\text { Ventilation }\end{array}$} \\
\hline \multirow{2}{*}{ Hospital Duration (Days) } & 16.50 & 15 & 24.0 & 28 & 16.0 & 10 & 26.00 & 32 & 17 & 17 & 22 & 26 \\
\hline & \multicolumn{4}{|c|}{$z=6.157 ; p<.001$} & \multicolumn{4}{|c|}{$z=4.661 ; p<.001$} & \multicolumn{4}{|c|}{$z=4.177 ; p<.001$} \\
\hline \multirow{3}{*}{ Cost after the 8th day $(\$)$} & 2211.2 & 6297.9 & 4202.2 & 7886.2 & 2355.1 & 4402.7 & 4524.1 & 9285.5 & 1774.2 & 6780.1 & 4016.9 & 7199.9 \\
\hline & & $z=4.74$ & $0<.001$ & & & $z=3.6$ & $p<.001$ & & & $z=3.1$ & $1 ; p=.002$ & \\
\hline & $\mathrm{n}$ & $\%$ & $\mathrm{n}$ & $\%$ & $n$ & $\%$ & $n$ & $\%$ & $\mathrm{n}$ & $\%$ & $\mathrm{n}$ & $\%$ \\
\hline Survival & & & & & & & & & & & & \\
\hline Living & 52 & 41.9 & 915 & 38.6 & 22 & 51.2 & 489 & 52.5 & 30 & 37.0 & 426 & 29.6 \\
\hline Died & 72 & 58.1 & 1454 & 61.4 & 21 & 48.8 & 443 & 47.5 & 51 & 63.0 & 1011 & 70.4 \\
\hline & & $\chi^{2}=0.5$ & $p=.461$ & & & $\chi^{2}=0.0$ & $p=.867$ & & & $\chi^{2}=1.9$ & $4 ; p<.158$ & \\
\hline Traumatic Brain Injury & & & & & & & & & & & & \\
\hline Hocnital Ruration (Rave) & 23 & 26 & 28 & 30 & 25 & 30 & 27.5 & 30 & 22 & 26 & 28 & 24 \\
\hline Hospital Duration (Days) & & $z=1.64$ & $p=.100$ & & & $z=0.0$ & $p=.989$ & & & $z=2.0$ & $p=.045$ & \\
\hline Cest after the 8th dav (\$) & 4016.9 & 7601.5 & 5429.1 & 8955.2 & 4324.8 & 8912.9 & 4777 & 9053 & 3942.8 & 7000.6 & 5965.8 & 8613.5 \\
\hline Cost aller tre oin ady (P) & & $z=2.47$ & $\mathrm{p}=.013$ & & & $z=0.8$ & $p=.408$ & & & $z=2.4$ & $p=.016$ & \\
\hline & $\mathrm{n}$ & $\%$ & $\mathrm{n}$ & $\%$ & $\mathrm{n}$ & $\%$ & $\mathrm{n}$ & $\%$ & $\mathrm{n}$ & $\%$ & $\mathrm{n}$ & $\%$ \\
\hline Survival & & & & & & & & & & & & \\
\hline Living & 861 & 38.0 & 106 & 47.1 & 431 & 51.2 & 80 & 59.7 & 430 & 30.1 & 26 & 28.6 \\
\hline Died & 1407 & 62.0 & 119 & 52.9 & 410 & 48.8 & 54 & 40.3 & 997 & 69.9 & 65 & 71.4 \\
\hline & & $\chi^{2}=7.2$ & $p=.007$ & & & $\chi^{2}=3.3$ & $; p=.069$ & & & $\chi^{2}=0.0$ & $9 ; p=.753$ & \\
\hline Major Wound & & & & & & & & & & & & \\
\hline Hospital Duration (Davs) & 23 & 27 & 24 & 27 & 25 & 31 & 22 & 30 & 22 & 26 & 31 & 26 \\
\hline Hospital Duration (Days) & & $z=1.50$ & $\mathrm{p}=.132$ & & & $z=0.2$ & $p=.821$ & & & $z=2.2$ & $p=.025$ & \\
\hline Cest after the 8th day (\$) & 4114.6 & 7791.1 & 4061.9 & 8125.5 & 4477.1 & 9119.5 & 3887.1 & 8348.1 & 3976.8 & 7069 & 4346.9 & 7950.0 \\
\hline Cost aller tre oun ady (P) & & $z=0.14$ & $\mathrm{p}=.887$ & & & $z=0.3$ & $p=.727$ & & & $z=0.4$ & $p=.653$ & \\
\hline & $n$ & $\%$ & $n$ & $\%$ & $n$ & $\%$ & $n$ & $\%$ & $n$ & $\%$ & $n$ & $\%$ \\
\hline Survival & & & & & & & & & & & & \\
\hline Living & 921 & 38.3 & 46 & 52.9 & 478 & 51.7 & 33 & 64.7 & 443 & 29.9 & 13 & 36.1 \\
\hline Died & 1485 & 61.0 & 41 & 47.1 & 446 & 48.3 & 28 & 35.3 & 1039 & 70.1 & 23 & 63.9 \\
\hline & & $x^{2}=7.5$ & $p=.006$ & & & $x^{2}=3.2$ & $p=.071$ & & & $\chi^{2}=0.6$ & $7 ; p=.421$ & \\
\hline Sepsis & & & & & & & & & & & & \\
\hline Hospital Duration (Davs) & 23 & 26 & 24 & 28 & 24 & 30 & 26.5 & 30 & 22 & 26 & 22 & 27 \\
\hline Hospital Luration (Days) & & $z=0.78$ & $\mathrm{p}=.433$ & & & $z=1.1$ & $p=.242$ & & & $z=0.3$ & $p=.703$ & \\
\hline & 3864.9 & 7240.3 & 4946.7 & 8264.5 & 4050.8 & 8401.1 & 5509.7 & 11864.2 & 3719.4 & 6715.1 & 4471.3 & 7626.2 \\
\hline Cost after the 8th day (\$) & & $z=5.11$ & $0<.001$ & & & $z=4.0$ & $p<.001$ & & & $z=3.5$ & $p<.001$ & \\
\hline & $\mathrm{n}$ & $\%$ & $\mathrm{n}$ & $\%$ & $\mathrm{n}$ & $\%$ & $\mathrm{n}$ & $\%$ & $\mathrm{n}$ & $\%$ & $\mathrm{n}$ & $\%$ \\
\hline Survival & & & & & & & & & & & & \\
\hline Living & 835 & 44.9 & 132 & 20.9 & 446 & 58.1 & 65 & 31.3 & 389 & 35.6 & 67 & 15.8 \\
\hline Died & 1025 & 55.1 & 501 & 79.1 & 321 & 41.9 & 143 & 68.7 & 704 & 64.4 & 358 & 84.2 \\
\hline & & $\chi^{2}=114$. & $; p<.001$ & & & $x^{2}=47$ & $6 ; p<.001$ & & & $\chi^{2}=57$. & $2 ; p<.001$ & \\
\hline Tracheostomy & & & & & & & & & & & & \\
\hline Hosnital Duration (Ravs) & 18 & 17 & 42 & 44 & 19 & 18 & 45 & 54 & 17 & 17 & 41 & 41 \\
\hline Hospital Duration (Days) & & $z=24.2$ & $p<.001$ & & & $z=15.1$ & $p<.001$ & & & $z=18.7$ & $; p<.001$ & \\
\hline & 2807.5 & 4550.1 & 9805.9 & 12456.2 & 2733.4 & 4521.8 & 11052.1 & 14963.6 & 2870.2 & 4615.2 & 9081.7 & 11421.2 \\
\hline Cost after the 8th day (\$) & & $\mathrm{z}=22.8$ & $p<.001$ & & & $z=15.0$ & $p<.001$ & & & $z=17.0$ & $5 ; p<.001$ & \\
\hline & $n$ & $\%$ & $n$ & $\%$ & $n$ & $\%$ & $n$ & $\%$ & $n$ & $\%$ & $n$ & $\%$ \\
\hline Survival & & & & & & & & & & & & \\
\hline Living & 649 & 37.5 & 318 & 41.6 & 341 & 53.0 & 170 & 51.2 & 308 & 28.4 & 148 & 34.3 \\
\hline Died & 1080 & 62.5 & 446 & 58.4 & 302 & 47.0 & 162 & 48.8 & 778 & 71.6 & 284 & 65.7 \\
\hline & & $\chi^{2}=3.7$ & $p=.054$ & & & $\chi^{2}=0.2$ & $p<.588$ & & & $x^{2}=5.1$ & $; p=.024$ & \\
\hline
\end{tabular}

M: Median value. IQR: Distance between Quartiles. z: Mann-Whitney U test; $\chi^{2}$ : Chi-square test 
PMV, TBI, tracheostomy, and major wound presence in the 65 and older age group increased hospital stay and costs. More work is needed to define $\mathrm{CCl}$ more clearly in elderly.

\section{REFERENCES}

1. Polastri $M$, Comellini $V$, Pisani L. Defining the prevalence of chronic critical illness. Pulmonology 2020;26(3):119-20. (PMID: 31812701)

2. Herridge MS, Tansey CM, Matte A, et al. Functional disability 5 years after acute respiratory distress syndrome. N Engl J Med 2011;364(14):1293-304. (PMID: 21470008)

3. Carson SS. Definitions and epidemiology of the chronically critically ill. Respir Care 2012;57(6):84856; discussion 56-8. (PMID: 22663962)

4. Laake JH, Dybwik K, Flaatten HK, et al. Impact of the post-World War II generation on intensive care needs in Norway. Acta Anaesthesiol Scand 2010;54(4):47984. (PMID: 19930244)

5. Boniatti MM, Friedman G, Castilho RK, Vieira SR, Fialkow L. Characteristics of chronically critically ill patients: comparing two definitions. Clinics (Sao Paulo) 2011;66(4):701-4. (PMID: 21655767)

6. Nelson JE, Meier DE, Litke A, et al. The symptom burden of chronic critical illness. Crit Care Med 2004;32(7):1527-34. (PMID: 15241097)

7. Vásquez-Revilla HR, Revilla-Rodríguez E, RaymundoAguilar CA, Gaytan-Sánchez BM, Terrazas-Luna $\checkmark$. Epidemiological characteristics of patients with chronic critical illness. An ambispective observational study. Medicina Interna de México 2017;33(2):16876. (in Spanish)

8. Iwashyna TJ, Hodgson CL, Pilcher D, et al. Timing of onset and burden of persistent critical illness in Australia and New Zealand: a retrospective, population-based, observational study. Lancet Respir Med 2016;4(7):566-73. (PMID: 27155770)

9. Kahn JM, Le T, Angus DC, et al. The epidemiology of chronic critical illness in the United States*. Crit Care Med 2015;43(2):282-7. (PMID: 25377018)

10. Guidet B, Leblanc G, Simon $T$, et al. Effect of Systematic Intensive Care Unit Triage on Long-

\section{Acknowledgements}

We would like to all clinician for this manuscript. There are no conflicts of interest in connection with this paper and the study was not use any sources of financial assistance.

term Mortality Among Critically III Elderly Patients in France: A Randomized Clinical Trial. JAMA 2017;318(15):1450-9. (PMID: 28973065)

11. Kwak SH, Jeong CW, Lee SH, Lee HJ, Koh Y. Current status of intensive care units registered as critical care subspecialty training hospitals in Korea. J Korean Med Sci 2014;29(3):431-7. (PMID: 24616595)

12. Heyland D, Cook D, Bagshaw SM, et al. The Very Elderly Admitted to ICU: A Quality Finish? Crit Care Med 2015;43(7):1352-60. (PMID: 25901550)

13. Milbrandt EB, Eldadah B, Nayfield S, Hadley E, Angus DC. Toward an integrated research agenda for critical illness in aging. Am J Respir Crit Care Med 2010;182(8):995-1003. (PMID: 20558632)

14. Bellani G, Laffey JG, Pham T, et al. Epidemiology, Patterns of Care, and Mortality for Patients With Acute Respiratory Distress Syndrome in Intensive Care Units in 50 Countries. JAMA 2016;315(8):788800. (PMID: 26903337)

15. Esteban A, Anzueto A, Frutos F, et al. Characteristics and outcomes in adult patients receiving mechanical ventilation: a 28-day international study. JAMA 2002;287(3):345-55. (PMID: 11790214)

16. Westphal GA, Vieira KD, Orzechowski $R$, et al. [Analysis of quality of life following hospital discharge among survivors of severe sepsis and septic shock]. Rev Panam Salud Publica 2012;31(6):499-505. (PMID: 22858817)

17. Stavem K, Hoel H, Skjaker SA, Haagensen R. Charlson comorbidity index derived from chart review or administrative data: agreement and prediction of mortality in intensive care patients. Clin Epidemiol 2017;9:311-20. (PMID: 28652813)

18. Rordorf G, Koroshetz W, Efird JT, Cramer SC. Predictors of mortality in stroke patients admitted to an intensive care unit. Crit Care Med 2000;28(5):13015. (PMID: 10834669) 